\title{
Evolução da Relação Médico-Doente
}

\section{Evolution of the Patient-Doctor-Relationship}

Ana Serrão Neto ${ }^{1^{*}}$

\section{RESUMO}

Faz-se uma análise da evolução histórica da relação-médico-doente (RMD) desde a Grécia antiga até ao século XXI, incluindo a influência das ciências sociais e da psicanálise. Reflete-se sobre a influência da internet, o empowerment dos doentes, as mudanças desencadeadas pelos grandes prestadores privados de saúde, e respetivas marcas, bem como pela medicina digital. Termina-se, alertando para aspetos essenciais que vão condicionar a RMD no futuro próximo.

PALAVRAS-CHAVE: Empoderamento; Relações Médico-Doente

\section{ABSTRACT}

This article outlines the historical evolution of the patient-doctor relationship (PDR) from ancient Greece to the $21^{\text {st }}$ century, including the influence of the social sciences and psychoanalysis. There is also a reflection about the influence of the internet, the empowerment of patients, changes caused by the new private health service providers and by digital medicine. The article finishes by highlighting essential aspects that will affect the PDR in the near future.

KEYWORDS: Empowerment; Physician-Patient Relations 


\section{INTRODUÇÃO}

Nestes tempos de aceleração exponencial da utilização de tecnologias na saúde, com implicações diretas na relação médico-doente, creio ser importante recordarmos o que tem sido esta relação ao longo dos tempos e os desafios que nos coloca a todos no presente e no futuro próximos.

\section{DEFINIÇÃO}

Pode definir-se a relação médico-doente (RMD) como uma relação consensual na qual o doente procura explicitamente o cuidado do médico e na qual o médico aceita explicitamente a pessoa como seu doente. Trata-se de uma relação humana altamente especializada, uma espécie de "Contrato" confidencial com a pessoa que procura ajuda, com respeito pela autonomia dessa pessoa, o doente. ${ }^{1}$ Tudo isto pressupõe uma relação ética e de confiança. A definição de RMD dada pelo nosso atual Bastonário é igualmente esclarecedora: "é o ato médico por excelência, da qual resulta uma história, um exame clínico e um conjunto de informações, medidas e decisões, que determinam o presente e o futuro do doente." 1

Como sabemos, a RMD depende das políticas de saúde, do espaço sociocultural e económico, do espaço geográfico e do espaço temporal onde é exercida, bem como do conhecimento científico, dos meios técnicos disponíveis e da personalidade do médico e do doente.

\section{RESENHA HISTÓRICA}

Na Grécia clássica, berço da nossa civilização e da democracia, a prática da medicina era baseada no raciocínio lógico e empírico. Assentava na observação do médico e decorria por tentativa e erro. O médico utilizava o seu conhecimento científico para guiar o doente, que cooperava com o médico. O objetivo era a cura da doença.

Foi aqui que nasceu o pensamento conceptual da medicina. Desenvolveram-se duas escolas, cujos princípios gerais ainda são atuais. ${ }^{1}$ A Escola de Cos, defendia uma abordagem holística. Estudava os efeitos globais da doença no organismo. Defendia que era importante ouvir o doente e as suas queixas, perceber o seu contexto. A RMD já era então considerada um elemento importante para o bem-estar do doente. Pelo seu lado, a Escola de Cnidus defendia uma abordagem reducionista. A doença era considerada uma entidade abstrata, separada do organismo. Esta escola descartava a influência de comportamentos e a experiência do doente; a RMD era considerada numa perspetiva essencialmente técnica.
O Juramento de Hipócrates, que data do século $\vee$ a.C., surgiu como consequência da prática médica de então. O objetivo era reger a conduta do médico e salvaguardar os direitos do doente, num sentido claramente humanista. Hipócrates afirmava: "A arte da medicina está em observar, curar algumas vezes, aliviar muitas vezes, consolar sempre".

Mais tarde, na Idade Média, a RMD foi profundamente marcada pela religião. Era uma relação paternalista, sendo o doente um sujeito passivo.

Do renascimento ao século XIX, registaram-se mudanças sociais profundas, desenvolveu-se o conhecimento científico. Recordemos o século XVIII, denominado século das luzes, e o século XIX influenciado pela corrente filosófica Positivismo. É neste século, em parte decorrente do positivismo, que nasce o conceito de Modelo Biomédico: um agente, uma doença, um tratamento. ${ }^{3}$ Assim, o médico aplicava ativamente os seus conhecimentos científicos num doente passivo. A RMD era ainda uma relação paternalista, em que o bom doente afirmava "O Sr. Dr. é que sabe, faça como entender".

No século XIX, o contributo da psicanálise foi relevante para o início da mudança desta RMD paternalista. No ato médico passou a dar-se mais ênfase ao papel central da comunicação com o doente e à história clínica. É bem expressiva desta época a recomendação de Sir W Osler "Listen to the patient".,4

No século XX nascem novos modelos conceptuais da $\mathrm{RMD}$, 3,4 dos quais se destacam dois: 1) o modelo funcional, de inspiração hipocrática, que preconizava que a prática clínica se devia centrar no doente como um todo e único. Este modelo entendia a doença dependente de fenómenos biológicos, sociais, culturais e psicológicos. Estava dada uma nova ênfase à história clínica; 2) o modelo biomédico, pelo seu lado, entendia a doença como entidade autónoma, desviando a atenção do doente para a doença e para a biologia. O Médico era considerado como engenheiro do corpo, pelo que a RMD era menos valorizada neste modelo.

O desenvolvimento das ciências sociais origina igualmente novas mudanças de conceitos. A saúde e a doença passaram a ser consideradas experiências socialmente construídas. A definição de saúde da OMS de $1947^{5}$ - "estado de completo bem-estar físico, mental e social e não somente ausência de doença" - é um exemplo deste novo conceito biopsicossocial. A prática da medicina volta a estar centrada na pessoa e na doença. A RMD ganha uma nova dimensão ao ser colocada no plano da empatia e com efeito terapêutico. É a esta luz que surge a afirma- 
ção tão expressiva do psicanalista Balint "O medicamento mais receitado pelo médico é o próprio médico".

Nos anos 50 nasce o conceito de Mutual Investment de Balint. ${ }^{6}$ Em particular nas especialidades que acompanham o doente ao longo de vários anos, como a pediatria e a medicina geral e familiar, em que a RMD é duradoura, dá-se significativamente realce à confiança, empatia e comunicação doente-médico.

Ao longo do século XX, ocorreram enormes avanços técnicos e científicos. A evolução global da ciência deu origem à pluridisciplinaridade. Com maior evidência na transição do século XX para o XXI, a evolução tecnológica e a especialização da medicina, transformou a RMD numa relação plural. ${ }^{7,8}$ O recurso a múltiplos meios complementares de diagnóstico (MCDT) e a diversas especialidades são os exemplos mais evidentes. Em consequência desta multidisciplinaridade a RMD deixa de ser uma relação pessoal de um para um, porquanto passam a existir vários intervenientes na relação. Há o doente e o médico inicial, mas também uma terceira e quarta pessoas, consoante as várias especialidades envolvidas. O melhor exemplo desta relação plural é o doente oncológico.

A RMD plural deu origem a novas reflexões, nomeadamente pela necessidade de ver o doente como um todo, de forma holística. É daqui que surge a prática clínica personalizada, ou seja, a medicina centrada no doente. ${ }^{7}$

Já na última década do século passado, surge nos EUA a medicina narrativa pela mão de Rita Charon. ${ }^{9}$ O objetivo passa a ser ouvir o doente, partilhar responsabilidade e poder, contrariar a despersonalização de cuidados decorrente da tecnologia e dos múltiplos atores envolvidos no cuidado ao doente. Alertava-se para a necessidade de estabelecer uma relação de confiança entre doente e médico, em que a reputação do médico é considerada essencial. É precisamente a propósito desta medicina que João Lobo Antunes escreveu "Ainda hoje o diagnóstico começa com a história clínica e o exame físico". ${ }^{10}$

\section{ATUALIDADE}

No século XXI, a evolução tecnológica tem sido enorme e rápida. A universalização dos smartphones e do acesso à internet aumentou a literacia em saúde, apesar dos conflitos entre informação e conhecimento, e contribuiu para o empowerment dos doentes. ${ }^{11}$ A tecnologia e a especialização no exercício da medicina continuam a aumentar. Acentua-se a prática plural da medicina. É nesta fase que nascem os hospitais privados, aos quais os médicos aderem mudando o consultório para estes novos espaços, onde o doente pode realizar, no mesmo local, tudo o que necessita para o diagnóstico e tratamento.

Com o nascimento dos hospitais privados, desenvolvem-se as marcas na saúde, que disputam a influência do doente a par da reputação do médico. A consequência natural é a publicidade na saúde. Entendendo-se publicidade como a forma de tornar público de forma apelativa e fundamentada uma proposta de valor para pessoas que vivem em ambiente de comunicação permanente. Vivendo a sociedade num ambiente de comunicação, é natural e lógica a publicidade em saúde, à qual o Serviço Nacional de Saúde também recorre.

Os grupos privados de saúde não tendo uma base fixa de doentes, têm um mercado para conquistar, pelo que é importante evidenciar as respetivas propostas de valor. Para maior eficácia, realizam estudos de mercado para apurarem os fatores que influenciam a escolha de uma marca.

Um estudo de mercado realizado em 2019 (Barómetro da Saúde 2019. Estudo de Mercado GfK - Recolha e análise estatística da informação - Estudo não publicado) identificou os seis principais fatores que influenciam a escolha de uma marca, os quais se enumeram por ordem decrescente de importância: competência clínica dos médicos; atenção e disponibilidade demonstrada pelos médicos; eficácia no processo marcação/marcação na data pretendida; tempo e espera até ser atendido consultas/exames; eficácia no processo de admissão; atenção e disponibilidade no serviço da receção. Por outro lado, os estudos também identificaram que para a ligação à marca contribuem as seguintes questões: hospitais com oferta global no mesmo local, marcas de confiança, especialistas de renome, acordos com múltiplos sistemas de saúde, processos administrativos fáceis, rapidez nas marcações, existência de unidades em rede e aplicações online.

Estes estudos permitem concluir que a competência clínica, a par de uma boa RMD, são fulcrais no processo de decisão de escolha de uma marca. Todavia, as facilidades logísticas e reputação das instituições privadas de prestação de cuidados de saúde também são valorizadas.

Em simultâneo com os grandes hospitais privados, a RMD muda por via da tecnologia digital. ${ }^{11} \mathrm{O}$ contacto médico-doente já não ocorre apenas na consulta, mas também via telemóvel, e-mail, fotografia e, mais recentemente, via teleconsulta.

Nas especialidades como a pediatria, medicina geral e familiar ou ginecologia a RMD é uma relação longitudinal, que se mantém ao longo de vários anos. É fundamental 
saber ouvir doentes e famílias.4,7,12 A profundidade desta relação nos tempos atuais implica skills em comunicação e empatia com o doente que gosta de recorrer ao Dr. Google antes da consulta médica.

Face a estes novos desafios que tem a RMD no século XXI, não podemos deixar de refletir no tema estratégico da formação médica universitária. Estaremos a dar a formação necessária à atitude profissional que nos novos tempos exigem? Na verdade, tanto os jovens médicos como os mais velhos, têm de aprender de modo empírico, a comunicar com o doente com a maior literacia de sempre em temas de Saúde.

\section{MENSAGENS A RETER}

A terminar, salientam-se alguns aspetos essenciais que, enquanto médicos, devemos conservar na nossa mente:

- Nunca podemos esquecer que nós, médicos, existimos por e para os doentes;

- A "Relação Médico-Doente" é tão importante, e intemporal, que justificou a candidatura a património imaterial da Humanidade em 2017;

- Podemos ter novas tecnologias, mas não temos novos valores;

- A relação médico-doente-marca veio para ficar;

- Uma Marca pode ser aglutinadora e geradora de confiança;

- Os prestadores privados existirão enquanto merecerem a confiança dos clientes e dos doentes;

- No admirável mundo novo, o doente será quem mais ordena;

- E nesse mundo novo, o médico ordenará consoante a sua capacidade de comunicação e empatia.

Nota: Conferência apresentada na 9a Reunião Pediátrica do Hospital CUF Descobertas.

\section{AGRADECIMENTOS/ ACKNOWLEDGMENTS:}

Ao Dr. Carlos Liz, pela amizade com que reviu o texto.

\section{RESPONSABILIDADES ÉTICAS}

CONFLITOS DE INTERESSE: Os autores declaram não possuir conflitos de interesse.

SUPORTE FINANCEIRO: O presente trabalho não foi suportado por nenhum subsídio ou bolsa.
PROVENIÊNCIA E REVISÃO POR PARES: Comissionado; sem revisão externa por pares.

\section{ETHICAL DISCLOSURES}

CONFLICTS OF INTEREST: The authors have no conflicts of interest to declare.

FINANCIAL SUPPORT: This work has not received any contribution grant or scholarship.

PROVENANCE AND PEER REVIEW: Commissioned; without external peer review.

\section{REFERÊNCIAS}

1. A Relação Médico-Doente: um contributo da Ordem dos Médicos. Lisboa: By the Book; 2019.

2. The Hipocratic Corpus. In: Roy Porter, editor. The Cambridge Illustrated History of Medicine. Cambridge: University Press; 1996.

3. Ong LM, de Haes JC, Hoos AM, Lammes FB. Doctor-patient communication: a review of the literature. Soc Sci Med. 1995; 40:903-18. doi: 10.1016/0277-9536(94)00155-m.

4. Kinmonth A, Stewart M. The patient-doctor relationship. In: Jones R, Britten N, Culpepper L, editors. Oxford Textbook of Primary Medical Care. Oxford: Oxford University Press; 2004

5. World Health Organization. [retrieved March 2020] Available from: https://www.who.int/fr/about/who-we-are/constitution.

6. Balint M. The doctor, his patient and the illness. London: Tavistock Publications; 1957.

7. Chipidza FE, Wallwork RS, Stern TA. Impact of the Doctor-Patient Relationship. Prim Care Companion. 2015.

8. Ribeiro da Silva A. Relação Médico Doente: uma revisão da literatura. [Tese Mestrado Universidade de Coimbra]. Coimbra: UC; 2016.

9. Charon R. Narrative and Medicine. N Engl J Med. 2004;26;350:862-4.

10. Lobo Antunes J. A Nova Medicina. Lisboa: Fundação Manuel dos Santos; 2012

11. Martin L, Dimatteo M. The Oxford Handbook of Health Communication and Behaviour Change. Oxford: Oxford Press; 2014

12. Delbanco T, Gerteis M. A patient-centered view of the clinician-patient relationship. Uptodate. [retrieved March 2020] Available from: https://www.uptodate.com. 